\title{
Resistencia y violencia política en la postdictadura chilena: el caso de Osorno, 1990-1994
}

Resumen: Este artículo explora las estrategias de resistencia y, en particular, las acciones de violencia política desarrolladas en la ciudad de Osorno durante los primeros años del periodo postdictatorial [1990-1994]. Toma como fuente principal la prensa local y algunas entrevistas. Este trabajo da cuenta de la existencia de acciones de violencia política, así como sus principales características, en el marco de un proceso de resistencia desarrollado en Osorno, pese a un contexto adverso influenciado por elementos históricos, políticos y sociales de carácter tanto nacional como local.

Palabras clave: violencia política, organizaciones rebeldes armadas, estrategias de resistencia.

\section{Resistance and political violence in post-dictatorship Chile: the case of Osorno, 1990-1994}

Abstract: This article reflects on the strategies of resistance, precisely the actions of political violence in Osorno city during the first years of the post-dictatorial period [1990-1994]. As primary sources it takes the local press and some interviews. This work shows the existence of actions of political violence, and also its essential characteristics in the frame of a resistance process developed in Osorno despite an adverse context influenced by historical, political, and social aspects of national and local character.

Keywords: political violence, armed rebel organizations, resistance strategies.

\section{Resistência e violência política no Chile pós-ditadura: o caso de Osorno, 1990-1994}

Resumo: Este artigo explora as estratégias de resistência e, especificamente, as ações de violência política desenvolvidas na cidade de Osorno durante os primeiros anos do período pós-ditadura [1990-1994]. Tem como fontes principais a imprensa local e algumas entrevistas. 0 principal resultado deste estudo é confirmar a existência de ações de violência política, assim como suas principais características, dentro de um processo de resistência desenvolvido em Osorno, apesar de um contexto adverso influenciado por elementos históricos, políticos e sociais de caráter nacional e local.

Palavras-chave: violência política, organizações rebeldes armadas, estratégias de resistência.

Cómo citar este artículo: Miguel Sepúlveda Chávez, "Resistencia y violencia política en la postdictadura chilena: el caso de Osorno, 1990-1994”, Trashumante. Revista Americana de Historia Socia/19 [2022]: 162-184.

DOI: 10.17533/udea.trahs.n19a08

Fecha de recepción: 15 de marzo de 2021

Fecha de aprobación: 2 de septiembre de 2021

Miguel Sepúlveda Chávez: Candidato a doctor de Ciencias Sociales en Estudios Territoriales de la Universidad de Los Lagos, Chile. Encargado del Archivo Histórico del Sur [CEDER]. ORCID: 0000-0001-6501-2203. Correo electrónico: miguelsepulvedachavez@gmail.com 


\section{Resistencia y violencia política en la postdictadura chilena: el caso de Osorno, 1990-1994}

Miguel Sepúlveda Chávez

\section{Introducción}

U na vez pactadas y consolidadas la transición democrática y el fin de la dictadura, distintos grupos y sectores vieron en este proceso una continuidad de la dictadura cívico-militar y su legado, lo que fue señalado en algunos casos como una salida burguesa ${ }^{1}$ y dio paso a lo que Manuel Antonio Garretón entenderá como un Chile postdictatorial. ${ }^{2}$

En efecto, entre las características que marcan este periodo está la permanencia de organizaciones rebeldes armadas, tales como el Frente Patriótico Manuel Rodríguez (FPMR), el Movimiento Juvenil Lautaro o MAPU-Lautaro, el Movimiento de Izquierda Revolucionaria (MIR), entre otras, las cuales apostaron por continuar con la resistencia y la lucha armada, así como con el uso de la violencia política contra el Estado chileno y los grupos hegemónicos. ${ }^{3}$ Lo anterior, incluso aunque existía un discurso anti-resistencia ${ }^{4}$ que las señaló como terroristas y enemigas del nuevo régimen democrático — entre otras cosas debido a que estos realizaron una serie de asaltos y atentados $-{ }^{5}$ y de la creación de organismos gubernamentales como el Consejo Coordinador de Seguridad Pública (CCSP). Finalmente, esto llevó a que, al terminar el gobierno de Patricio Aylwin en 1994, la

1. Igor Goicovic Donoso, “Transición y violencia política en Chile (1988-1994)”, Ayer 79.3 (2010): 59-86.

2. Manuel Antonio Garretón, Neoliberalismo corregido y progresismo limitado. Los gobiernos de la concertación en Chile, 1990-2010 (Santiago: Editorial Arcis / CLACSO, 2012).

3. Nicolás Acevedo Arriaza, "Continuidades en el Chile post-dictatorial: el accionar del MAPULautaro y la respuesta de la Policía de Investigaciones en el gobierno de Patricio Aylwin (1990)", Revista Divergencia 4 (2013): 73-101.

4. Miguel Sepúlveda Chávez, "Evolución del discurso anti-resistencia en la dictadura militar chilena. El caso de Osorno, 1973-1994", Religación. Revista de Ciencias Sociales y Humanidades 1.3 (2016): 55-75.

5. Acevedo Arriaza. 
lucha insurgente, o al menos la de estas organizaciones y sujetos, fuera vista como derrotada. ${ }^{6}$

La ciudad de Osorno (Región de Los Lagos, Chile) no es una excepción a este contexto. Sin embargo, debido a que la mayoría de las investigaciones sobre la temática se han enfocado en los centros político-administrativos del país, existe un vacío respecto a cómo se desarrolló el proceso y el periodo anteriormente descrito en territorios que pueden ser considerados como periféricos, tanto geográfica como administrativamente.

Así, resulta de interés revisar las estrategias de resistencia en general y, en específico, las acciones de violencia política desarrolladas por grupos, organizaciones y sujetos en un contexto territorial como el de Osorno, en el cual, además, durante al menos todo el siglo XX se desarrollaron procesos históricos y sociales que marcaron la configuración de sus relaciones de poder. ${ }^{7}$ Es por ello que el objetivo del presente trabajo es explorar las estrategias de resistencia, y específicamente las acciones de violencia política desarrolladas en la ciudad de Osorno durante los primeros años del periodo postdictatorial, de 1990 a 1994.

Desde el punto de vista metodológico, y en relación con las fuentes utilizadas, se recurrió principalmente a la revisión y el análisis de la prensa local, específicamente del periódico El Austral de Osorno, creado en 1982 y editado por la Sociedad Periodística Araucanía, S.A., perteneciente al conglomerado El Mercurio S.A.P. Asimismo, se revisaron fuentes primarias orales, correspondientes a entrevistas en profundidad realizadas a dos personas que participaron en el proceso de resistencia en Osorno durante el periodo de estudio. ${ }^{8}$ Todo lo anterior, complementado con la revisión de literatura científica especializada.

Para dar cumplimiento al objetivo señalado, el trabajo se dividirá en cuatro partes. En la primera de ellas se abordarán de manera teórica dos conceptos que se relacionan directamente con el caso de estudio: resistencia y violencia política. En la segunda, se revisará el contexto histórico-social a nivel nacional en el que se inserta la investigación. En la tercera, se revisará de manera general el contexto postdictatorial y el proceso de resistencia desarrollado en Osorno durante el periodo, para, finalmente, en la cuarta parte, describir las acciones de violencia política desarrolladas en la ciudad de Osorno.

6. Goicovic Donoso 59-86.

7. Miguel Sepúlveda Chávez, "Osorno como territorio en disputa. Una revisión a través del imaginario hegemónico y los procesos de resistencia durante el siglo XX", Identidades 20 (2021): 20-36.

8. Tanto Miguel como Ricardo participaron activamente en organizaciones tales como el MIR, FPMR y MAPU-Lautaro. Sin embargo, en sus propias palabras, ellos no se veían como militantes (en un sentido tradicional) de ninguna de ellas. Entrevista de Miguel Sepúlveda a Miguel y Ricardo, Osorno, agosto de 2015. 


\section{Resistencia y violencia política}

En el desarrollo de este trabajo, las acciones desarrolladas por los sujetos y grupos insurgentes serán entendidos bajo dos categorías: resistencia y violencia política. Respecto al concepto de resistencia es pertinente señalar que una contribución importante a su vigencia se debe a los aportes de Michel Foucault respecto al poder. De acuerdo con Foucault, no existen relaciones de poder sin resistencias. ${ }^{9}$ Toda vez que nazca una relación de poder existirá la posibilidad de resistencia. ${ }^{10}$

La resistencia es un proceso contra la dominación. ${ }^{11}$ Esta sería una estrategia para transformar conflictos e intervenir sobre las asimetrías de poder. ${ }^{12}$ De acuerdo con James Scott, es de una forma mucho más indirecta u oculta que esta se manifiesta mientras existe un contraste entre la conducta de los poderosos y quienes carecen de poder, lo que evita, al menos temporalmente, un enfrentamiento directo. ${ }^{13}$ Sin embargo, esto no contradice que en algún momento logre impactar en lo público y hacerse visible. Ejemplo de ello son las diferentes estrategias de resistencia desarrolladas durante la dictadura cívico-militar en la provincia de Osorno, que van desde ollas comunes, distribución de panfletos, peñas folclóricas hasta las barricadas, cortes de luz, uso de explosivos, uso de armas, entre otras. ${ }^{14}$

Según Gerrit Burgwal, este comportamiento clandestino o indirecto radica en el hecho de que para los grupos y sujetos que se encuentran en posiciones o condiciones desfavorables “que actúan abiertamente, o más aun, que se rebelan, esto puede poner en peligro su subsistencia". ${ }^{15}$ En consecuencia, "intentan evitar el desafio directo y tratan de 'trabajar el sistema' por medio de prácticas cotidianas de resistencia que van desde el rumor y el chisme hasta el sabotaje y el hurto". ${ }^{16}$ Así, los procesos de resistencia poseerían diferentes expresiones que irían desde "acciones individuales hasta movimientos colectivos, masivos, de temporalidad relativa y estructurados. [La resistencia] Se expresa de diversas maneras, definiendo una amplia gama de recursos a los cuales pueden apelar las personas o comunidades a quienes incumba esta acción". ${ }^{17}$

En definitiva, los grupos contrahegemónicos desarrollarían estrategias de resistencia ligadas de manera fuerte a la astucia y cada una constituiría un proceso específico contra la dominación en función de un contexto y una coyuntura

9. Michel Foucault, Microfisica del poder (Madrid: La Piqueta, 1978).

10. Reinaldo Giraldo Díaz, "Poder y resistencia en Michel Foucault", Tabula Rasa 4 (2006): 103-122.

11. Nelson Molina Valencia, "Resistencia comunitaria y transformación de conflictos", Revista Reflexión Política 7.14 (2005): 70-82.

12. Molina Valencia 73.

13. James C. Scott, Los dominados y el arte de la resistencia. Discursos ocultos (México: Ediciones Era, 2000).

14. Miguel Sepúlveda Chávez, "Mecanismos de resistencia en la ciudad de Osorno, en el contexto de dictadura militar, 1973-1990", Scientia Plena 10.12 (2014): 1-12.

15. Gerrit Burgwal, Prácticas cotidianas de resistencia (Montevideo:Tierra Nueva, 1970) 165.

16. Burgwal 65.

17. Molina Valencia 71. 
específica. Las resistencias poseen una singularidad, una identidad propia, que las define en relación con quienes las ejercen. Para el caso específico de este trabajo, esta identidad respondería a un contexto social y político en el cual estos grupos son percibidos como extemporáneos, además de un peligro para el recuperado orden democrático. Asimismo, un grupo específico de las estrategias de resistencia serán analizadas dentro del ámbito de la violencia política, por lo cual resulta necesario comprender lo que se entiende sobre este concepto.

Un primer acercamiento a la violencia política parte de comprender la violencia en general. Esta se distingue de la ira y la agresividad, ya que, a diferencia de la primera, que es expresión de "una actitud hostil hacia una situación en la que intervienen personas, objetos o ambos, prorrumpe en actos de fuerza desmesurada y busca desestructurar cuerpos y valores de uso", ${ }^{18}$ y de la segunda, entendida como una "afección que actúa bajo la lógica del coraje para embestir la realidad con dureza", ${ }^{19}$ la violencia es un proceso y una voluntad materializada que intenta "imponer una situación y las formas de su valoración (moral y cognitivamente; por eso no hay violencias irracionales, porque toda violencia tiene el vigor para imponer una razón) a través del uso de una fuerza o de un conjunto de fuerzas (materiales, simbólicas, cognitivas, afectivas)". ${ }^{20}$ Además, no sería un acto singular, sino que, por el contrario, se trataría de "un conjunto articulado de prácticas contenciosas, cuyo fin es la producción de diferencias (en la violencia no se persigue la igualdad, sino la distinción, la ruptura de la identidad por la fuerza)". ${ }^{21}$

Para Tamara Jorquera-Álvarez e Isabel Piper Shafir, la violencia sería una forma de calificar acciones sociales en contextos determinados, ejercida dentro de las relaciones de poder, lo que implicaría "que no es un fenómeno único, sino que la acción es designada y connotada desde diversas posiciones, teniendo como efecto su legitimación o deslegitimación". 22

Así, de manera más precisa, la violencia política se entiende como "una forma particular y especial de violencia, la cual se centra de preferencia en el conflicto (vertical) entre gobernantes y gobernados, entre grupos dominantes y subalternos, de 'arriba abajo' o ‘abajo arriba"'. ${ }^{23}$ Por ello, la violencia política consistiría "en el empleo consciente - aunque no siempre premeditado- de la amenaza del uso de

18. Daniel Inclán y Aurelia Valero, "Reporte del tiempo: presente e historia”, Desacatos. Revista de Ciencias Sociales 55 (2017): 60-73, doi: 10.29340/55.1804.

19. Inclán y Valero 65.

20. Daniel Inclán, "Contrapuntos: la crueldad contra el cuidado (o cómo la violencia se hace cotidiana)", Bajo el Volcán 16.24 (2016): 13-31.

21. Inclán 15.

22. Tamara Jorquera-Álvarez e Isabel Piper Shafir, "Revisión de estudios sobre violencias políticas realizados en la última década", Psicoperspectivas 17.3 (2018): 1-13.

23. Danny Monsálvez Araneda y Yerko Aravena Constanzo, "Interpretaciones historiográficas sobre la violencia política en Chile", Folia Histórica del Nordeste 32 (2018): 83-99, doi: 10.30972/ fhn.0323498. 
la fuerza fisica por parte de individuos, entidades, grupos o partidos que buscan el control de los espacios de poder político". ${ }^{24}$

Por otra parte, en tanto que la violencia puede ser instrumentalizada desde ambas partes en las relaciones de poder, se podrían considerar como violencias políticas tanto las ejercidas por el Estado, sus agentes y los grupos hegemónicos, así como las que provienen de personas o grupos resistentes al ejercicio del poder. ${ }^{25}$ En definitiva, las violencias políticas serían "aquellas que ocurren en el marco de acciones dirigidas a preservar, modificar, sustituir o destruir el modelo de Estado o de sociedad vigente [...] siendo utilizada tanto por el poder como por la resistencia", ${ }^{26}$

Para efectos de este trabajo, la investigación se centrará principalmente en las violencias utilizadas por la resistencia. Estas violencias políticas, así como el proceso de resistencia en el que están inmersas, deben ser comprendidas y estudiadas dentro del contexto histórico-social en el que se desarrollan. Por ello, en el siguiente apartado se revisará dicho contexto.

\section{Transición democrática y el Chile postdictatorial}

A partir de la campaña plebiscitaria y el plebiscito de octubre de 1988, se dio inicio al proceso que ha sido denominado como de transición democrática. Este proceso, gestado en la dictadura, no estuvo exento de oposiciones, representadas principalmente por aquellas organizaciones armadas o insurgentes que iniciaron su actividad, ya sea durante la década de 1980, como fue el caso del FPMR y MAPULautaro, o mucho antes, como sucedió con el MIR, fundado en 1965. Estas organizaciones vieron en la transición democrática, no una salida que permitiera la toma del poder y la instalación de un nuevo orden político, económico y social, sino más bien un régimen alternativo a la dictadura. ${ }^{27}$

Es por ello que cada una de estas organizaciones definió sus propios planteamientos respecto a cómo se tenía que dar fin a la dictadura y cómo debía ser construida la sociedad una vez realizado lo anterior. Así, por ejemplo, el MAPU-Lautaro, en un congreso desarrollado en enero de 1988, planteó que la dictadura debía ser derrocada "mediante una 'Guerra Insurreccional de Masas'. Dicho conflicto armado estaba sustentado bajo la lógica que en Chile dominaba una tríada que tenía como base de las Fuerzas Armadas, las grandes transnacionales y los grupos económicos". ${ }^{28}$ Este proyecto "sería para el ML legítimo, independiente del resultado del Plebiscito, porque según su concepción, quienes dominaban era la antes mencionada tríada". ${ }^{29}$

24. Monsálvez Araneda y Aravena Constanzo 87.

25. Jorquera-Álvarez y Piper Shafir 2.

26. Jorquera-Álvarez y Piper Shafir 3.

27. Luna Follegati Montenegro, "Estrategias analíticas de la Transición a la Democracia: la clave del pasado como perspectiva de futuro", Rosa 1 (2019): 41-61.

28. Acevedo Arriaza 81.

29. Acevedo Arriaza 81 
Para el caso del MIR, y los diferentes grupos derivados del mismo, se puede señalar que estas organizaciones enfatizaron en dos aspectos fundamentales su crítica a la transición, por una parte, "la ausencia de una 'alternativa popular y revolucionaria' y, por otra, 'la claudicación y subordinación de la izquierda (tradicional) a la burguesía". ${ }^{30}$ Así, se instalaba en estas organizaciones el pensamiento de que tanto aquellos que buscaban continuar con el legado pinochetista como la naciente Concertación de Partidos por la Democracia (en adelante, Concertación) "representaban los intereses del 'imperialismo' y del 'gran capital financiero' y sólo discrepaban respecto de las formas específicas que debía asumir el modelo de dominación". ${ }^{1}$

Por otra parte, el FPMR-Autónomo (fracción escindida del Partido Comunista) adoptó en octubre de 1988, la estrategia de Guerra Patriótica Nacional (GPN). En esta propuesta, la dirección del FPMR-Autónomo "estableció en el mes de abril de 1988 que el plebiscito que se realizaría en octubre de ese mismo año, independiente de los resultados que podían arrojar las urnas, sólo favorecería la continuidad del modelo de dominación impuesto por la dictadura militar y la burguesía monopólico-financiera". ${ }^{32}$ Esta nueva estrategia fue puesta en práctica el mismo 1988, y se tradujo en la ocupación de cuatro poblados rurales (La Mora, Aguas Grandes, Pichipellahuén y Los Queñes) el 21 y 22 de octubre, “con objeto de generar las condiciones para la construcción gradual del "ejército del pueblo", 33

El resultado del plebiscito en Chile dio por vencedora a la opción del "No", con lo cual se dio paso a las elecciones presidenciales de 1989, que tuvieron como ganador a Patricio Aylwin, demócrata cristiano, representante de la Concertación, quien obtuvo la mayoría de la votación, con un 55.2\%. El 11 de marzo de 1990, Aylwin asumió como presidente de Chile.

A partir de lo visto anteriormente, era de esperarse que las acciones de resistencia o violencia política continuaran haciéndose presentes durante el gobierno de Aylwin. A nivel nacional, se ha estimado que el periodo de mayor importancia para este tipo de acciones fueron los primeros 15 meses del gobierno de Aylwin, y comenzó a declinar a partir del asesinato de Jaime Guzmán. ${ }^{34}$ Así, al cumplirse el primer año del nuevo gobierno democrático, Aylwin señaló que "una de las principales preocupaciones para ese año sería el 'combate' contra la delincuencia y el terrorismo". ${ }^{35}$ Tal como señala Nicolás Acevedo, esta actitud desde el gobierno se establecería debido a que:

30. Goicovic Donoso 76.

31. Goicovic Donoso 76.

32. Goicovic Donoso 70.

33. Goicovic Donoso 78.

34. Pedro Feria Vázquez, "Del mediterráneo al cono sur: las transiciones a la democracia de Chile, Portugal y España en perspectiva comparada", Revista de Historia Social y de las Mentalidades 22.2 (2018): 103-135.

35. Goicovic Donoso 82. 
Las aspiraciones populares fueron apaciguadas mediante la concepción de que se estaba viviendo una transición a la democracia, para lo cual se debía tener cautela, fomentando la reconciliación entre los chilenos. En ese escenario, la presencia y el actuar de organizaciones como el MAPU-Lautaro fueron percibidas por dicho gobierno, como peligrosas para consagrar el régimen democrático. Al contrario, las organizaciones rebeldes armadas, concibieron el retorno de la democracia como la continuación de la herencia dictatorial, reflejado en el modelo económico neoliberal y en el sistema político poco participativo. ${ }^{36}$

Esto último explicaría los diferentes procesos y estrategias de resistencia a nivel general que fueron desarrollados durante el periodo a lo largo del territorio nacional. Bajo este contexto, el gobierno de Aylwin desarrolló e implementó una serie de elementos en función de deslegitimar, desarmar y controlar dichas organizaciones:"se diseñó un entramado normativo que endureció las penas contempladas en el Código de Justicia Militar, en la Ley de Seguridad Interior del Estado, en la Ley de Control de Armas y Explosivos y en la Ley Antiterrorista". ${ }^{37}$

Estos lineamientos estatales respecto a las organizaciones rebeldes armadas se tradujeron en las detenciones de un número importante de sus militantes, así como también en acciones de violencia estatal. Como se vio en la sección anterior, el uso de la violencia con fines políticos no es exclusivo de ciertos grupos y sectores. Cuando es desarrollada por parte de los grupos hegemónicos, algunas de las formas y dinámicas sociales que adquiere en un momento de conflicto político serían: "la violencia coercitiva que tiene como objetivo persuadir a los oponentes para que concluyan o reduzcan sus acciones políticas. La violencia lesiva que pretende castigar y la violencia destructiva cuyo su objetivo es la exterminación". ${ }^{38}$ Cada una de ellas respondería a contextos específicos de aplicación, además de no ser excluyentes entre sí. ${ }^{39}$ En este caso, una de las violencias que fue utilizada contra integrantes de estas organizaciones, y que permitió, en conjunto con otras estrategias y mecanismos, abortar los procesos desarrollados por las organizaciones armadas, fue la tortura, tanto física como psicológica — para el periodo de 1990 a 1994, la Corporación de Promoción y Defensa de los Derechos del Pueblo (CODEPU) registró 140 denuncias de tortura-,${ }^{40} \mathrm{y}$ destacó la participación de la Policía de Investigaciones de Chile en su ejecución. ${ }^{41}$

Esta lógica anti organizaciones rebeldes — así como las prácticas asociadas a ella- permeó a lo largo del territorio chileno. No obstante, tal como se ha señalado, tanto a nivel nacional, como en Osorno, territorio de estudio para este trabajo,

36. Acevedo Arriaza 93.

37. Goicovic Donoso 86.

38. Monsálvez Araneda y Aravena Constanzo 87.

39. Monsálvez Araneda y Aravena Constanzo 87.

40. Corporación de Promoción y Defensa de los Derechos del Pueblo (CODEPU), Informe Derechos Humanos 1990-1994 (Santiago: [s.e.], 1994) 15-16.

41. Acevedo Arriaza 90-92. 
durante el periodo 1990-1994 fueron desarrolladas estrategias de resistencia por las organizaciones señaladas y por otros grupos y sujetos. Cabe preguntarse entonces cómo se desarrollaron estas estrategias en la ciudad de Osorno, ¿cuáles fueron sus características? ¿cuál fue el contexto en el que se desarrollaron? La siguiente sección busca responder parcialmente estas preguntas.

\section{Contexto postdictatorial y estrategias de resistencia en Osorno}

La ciudad de Osorno, fundada inicialmente en 1558 en territorio mapuche-williche, vivió un proceso de refundación y repoblamiento a fines del siglo XVIII (en 1603 fue destruida y, en consecuencia, los mapuche-williche recuperaron el territorio). De ahí en más, su desarrollo histórico-social estuvo ligado a algunos procesos como la colonización alemana a mediados del siglo XIX, el auge político y económico alcanzado durante la primera mitad del siglo XX, entre otros. ${ }^{42}$

Entre las características que destacan de este territorio, y que resultan interesantes para este trabajo, se encuentra, por una parte, la existencia de un imaginario sociopolítico que la señala como una ciudad clasista, elitista, racista y ligada a tendencias de carácter más conservadoras, el cual puede ser corroborado a partir de diversos relatos, ya sea de quienes participaron en procesos de resistencia en el periodo dictatorial y postdictatorial, como también de personas nacidas en Osorno o que vivieron en ella y que tienen o tuvieron cierta notoriedad pública. Por otra parte, e incluso a pesar de lo anterior, está la presencia de algunos grupos subalternos y/o contrahegemónicos que han llevado a cabo procesos de resistencia. Todo ello, permite pensar en Osorno como un territorio en disputa, en el cual existe "una tensión o disputa territorial por parte de aquellos grupos que buscan mantener, modificar, subvertir y/o eliminar las relaciones de poder, la que puede ser rastreada con cierta claridad al menos desde y durante el siglo XX". ${ }^{43}$ Así, el proceso y las estrategias de resistencia, entre ellas las acciones de violencia política desarrolladas durante el periodo 1990-1994 serían expresiones de dicha tensión.

Lo anterior implica, entre otras cosas, que existía un contexto local aparentemente adverso a procesos contrahegemónicos de resistencia (visibilizado por medio de la existencia del mencionado imaginario sociopolítico dominante) que, sumado al entorno nacional descrito anteriomente, representaría una dificultad aún mayor para el desarrollo, por parte de todos aquellos grupos y organizaciones descontentos con el proceso transicional, de estrategias de resistencia, las cuales, no obstante, igualmente existieron.

Las estrategias de resistencia desarrolladas en Osorno entre 1990 y 1994, probablemente de la misma forma que en el resto del territorio nacional, se enmarcan

42. Víctor Sánchez Aguilera, El pasado de Osorno. La gran ciudad del porvenir (Osorno: Municipalidad de Osorno, 1948); Jorge Muñoz Sougarret, "Introducción", Osorno, la ciudad moderna del sur de Chile. Salubridad, sociabilidad y discursos. Primera mitad del siglo XX, Simón Fernández Parra y otros (Osorno: Editorial Universidad de Los Lagos, 2016) 9-14.

43. Sepúlveda Chávez, "Osorno como territorio". 
en un proceso de resistencia desarrollado en años anteriores, y tenían como antecedente más directo lo ocurrido durante la dictadura cívico-militar, sobre todo en la segunda mitad de la década de 1980: “del 86 en adelante, hubieron 6-7 años de organización, fuerte, donde sí hubo harta [mucha] resistencia, hubo harto [mucho] sabotaje, harta [mucha] organización". ${ }^{44}$ De acuerdo con Miguel, quien participó en la resistencia de la ciudad, a partir de la segunda mitad de la década de 1980, en Osorno "se empieza a dar una pelea un poco más frontal". ${ }^{45}$ Para la época, además, señala la presencia de algunas organizaciones en la ciudad: "en ese tiempo [19861987] estaba en un principio el MIR [...] también estaban en ese tiempo, lo que era el Frente Patriótico, lo que era el Lautaro". ${ }^{46}$

Desde su inicio, el gobierno de Aylwin estuvo marcado tanto por la presencia de organizaciones rebeldes armadas, inconformes con el proceso de fin de la dictadura y transición democrática, como por los intentos de desarticularlas bajo el discurso de ser una amenaza para el nuevo régimen democrático. Esto último se tradujo en un mejoramiento de los aparatos represivos. Así, en el caso de Osorno, lo anterior condujo a un proceso de migración hacia el centro del país por parte de quienes participaron en la resistencia: "La gente comenzó a moverse [...] producto de la repre [represión], los cabros se van, están operando en Temuco, Conce [Concepción], después ya cada vez replegándose más llegan a Santiago, ahí terminan de caer los últimos compas [compañeros]". ${ }^{47}$

A partir de ello, se vio una disminución de las acciones de estos grupos en Osorno, ya que, como recuerda Ricardo, quien, al igual que Miguel, fue partícipe del proceso de resistencia en Osorno: "en el 92 quedamos semiclandestinos". ${ }^{48}$ Esto significó una mayor dificultad para actuar, algo que, de acuerdo con el relato de Miguel, se esperaba desde el inicio del periodo postdictatorial:

Era una hueá [cosa] más desordenada, nosotros igual cachábamos [sabíamos] que la hueá [cosa] se venía pesada, porque no había por dónde ganarles, ya los otros hueones [sic] de izquierda se habían ido pa' otro lado [...] estaban en otra parada, y obviamente que [...] después del noventa los hueones [sic] crean "La Oficina" que son los mismos hueones [sic], que empiezan a entregar gente $[\ldots]$ era obvio que se venía así la mano [cosa]. ${ }^{49}$

En relación con lo último, en el año 1991, por medio del Decreto Supremo 363, se crea el CCSP, más conocido como "La Oficina", un organismo encargado de "procesar la información de inteligencia y seguridad referida a los grupos insurgentes y, a la vez, coordinar los distintos destacamentos policiales en las operaciones

44. Entrevista de Miguel Sepúlveda Chávez a Miguel, Osorno, agosto de 2015.

45. Entrevista a Miguel.

46. Entrevista a Miguel y Ricardo.

47. Entrevista a Miguel.

48. Entrevista de Miguel Sepúlveda Chávez a Ricardo, Osorno, agosto de 2015.

49. Entrevista a Miguel. 
de neutralización de la acción armada". ${ }^{50}$ Entre sus principales acciones, destacó la infiltración en las organizaciones armadas, lo cual resultó fundamental para desarticular los diferentes procesos de resistencia. Así, en conjunto con la violencia ejercida por parte del Estado, el crear y mantener una sensación de desconfianza, al igual que en el periodo dictatorial, ${ }^{51}$ fue una estrategia recurrente para intentar desarticular los procesos de resistencia. Esto es constatado por Ricardo:

Los hueones [sic] que estaban en la moneda [...] ellos crearon su respuesta frente a esa juventud que ellos mismos habían educado en la subversión o con ideas de resistencia [...] empezaron a crear la desconfianza, reclutaron caleta de gente [mucha gente] que antes era "popular" digamos, que conocía a todo el mundo, los reclutaron en La Oficina [...] nuestro apoyo siempre estuvo en la población, los hueones [sic] se incrustaron en las poblaciones, buscaron información en las poblaciones, solamente para reprimir, hubo caleta de [muchos] cabros que no tenían una militancia clara digamos, del MIR, del Frente, pero si apoyaban todas las causas, como nosotros cachay [sic] [...] todos esos locos en cana [en la cárcel] [...] una represión enorme, [...] y la gente obvio po', en las poblaciones decían, no yo no escondo a esta gente porque no me quiero ir en cana [a la cárcel] po', y la desconfianza [...] este sapeó [delató], este no. ${ }^{52}$

La creación de La Oficina y la participación de exintegrantes de las diferentes organizaciones rebeldes armadas en ella sin duda fueron golpes bastante fuertes para quienes continuaron luchando en la postdictadura, sobre todo porque fue principalmente gracias a la información y el conocimiento entregados por estas personas a dicho organismo que se desarrolló, y de manera exitosa, un proceso de detención y persecución de quienes continuaron su lucha en el periodo postdictatorial.

A pesar del contexto adverso, tanto a fines de la dictadura, como durante el gobierno de Aylwin, se desarrollaron diversas estrategias de resistencia en la ciudad. Entre ellas, aquellas de propaganda armada son especialmente recordadas por Ricardo: "Hicimos como varias bonitas experiencias acá de propaganda [...] la que más me gustó en realidad fue bien simbólica, que se llaman propaganda armada, donde tú sales con toda tu gente [...] armados, encapuchados, tus banderas, pegas [das] tus gritos [...] te acercas a la gente, le repartes propaganda" ${ }^{53}$ Este tipo de acciones fueron realizadas, aunque no de manera exclusiva, en algunas fechas específicas por su importancia simbólica. Entre las más significativas, se encuentran el 11 de septiembre, en referencia al golpe de y la posterior instalación de la dictadura cívico-militar, y el 29 de marzo, conocido en la actualidad como el Día del Joven

50. Goicovic Donoso 84.

51. Miguel Sepúlveda Chávez, "Mecanismos de control en la ciudad de Osorno: contexto de dictadura militar, 1973-1990”, Diálogos. Revista Electrónica de Historia 16.1 (2015): 215-239.

52. Entrevista a Ricardo.

53. Entrevista a Ricardo. 
Combatiente, en conmemoración al asesinato de los hermanos Rafael y Eduardo Vergara Toledo cometido por agentes de carabineros de Chile en 1985.

Las propagandas armadas y las acciones directas o de violencia política (asaltos, bombas, tiroteos, entre otras) que serán revisadas en detalle en la sección posterior no fueron las únicas estrategias desarrolladas en la época, pues, a la par, se realizaron actividades culturales en diferentes sectores: "Aparte de las acciones más densas [...] igual hacíamos trabajo político-social, igual nos organizábamos, por ejemplo, teníamos un centro cultural [...] que era como nuestra base política de operaciones, porque ahí nosotros hacíamos hueás [cosas, actividades] en las poblaciones, hacíamos hartas [muchas] actividades, hartas [muchas] actividades culturales, en sedes sociales". 54

De manera general, se ha descrito el contexto y algunas características del proceso de resistencia desarrollado en este territorio durante el gobierno de Aylwin, sin embargo, como se declaró con anterioridad, interesa revisar de manera más específica y detallada aquellas estrategias consideradas como violencia política. En la siguiente sección se pretende describir dichas acciones.

\section{Acciones de violencia política en Osorno}

A partir de la revisión del periódico El Austral de Osorno para el periodo 19901994, se pudo constatar la existencia de al menos 27 acciones de violencia política desarrolladas en Osorno por diferentes grupos u organizaciones. De ellas, tal como se aprecia en la Tabla 1, más de la mitad se concentra en el primer año del periodo postdictatorial (16 acciones, correspondientes al 59\%), lo que se condice con la tendencia a nivel nacional comentada en secciones anteriores, con una baja considerable para los años posteriores. Asimismo, con base en una clasificación simple, se establecieron nueve categorías para estas acciones: a) amenaza o advertencia, ya sea presencial o vía telefónica; b) asalto o robo; c) ataque / atentado contra edificación; d) ataque / atentado contra comisaría o retén de carabineros; e) aviso de bomba o falsa bomba; f) bomba en edificio (no considera edificios policiales ni religiosos); g) bomba en edificio de carabineros; h) bomba en templo o iglesia, e i) disparos contra carabineros.

Del repertorio de acciones desarrolladas, es posible señalar que el asalto o robo y el uso de bombas en diferentes edificaciones fueron los tipos de acciones más recurrentes, cada una repetida y registrada en ocho ocasiones, por lo que ambas concentraron el 56\% del total de acciones de violencia política en el periodo. El 41\% restante se distribuyó de manera relativamente homogénea entre las otras cinco categorías. Respecto a los asaltos o robos, tres cuartas partes de estos se realizaron en el primer año del periodo postdictatorial, y registraron un descenso importante durante los años posteriores, hasta incluso desaparecer entre 1992 y 1993. Por su parte, el uso de bombas fue registrado prácticamente durante todo el

54. Entrevista a Miguel. 
Tabla 1. Cantidad y tipo de acciones de violencia política por año

\begin{tabular}{|c|c|c|c|c|c|c|c|}
\hline Tipos de acciones & 1990 & 1991 & 1992 & 1993 & 1994 & Total & Porcentaje \\
\hline Amenaza o advertencia & 3 & - & - & - & - & 3 & 11.1 \\
\hline Asalto o robo & 6 & 1 & - & - & 1 & 8 & 29.6 \\
\hline $\begin{array}{l}\text { Ataque/atentado contra } \\
\text { edificación }\end{array}$ & 1 & - & - & - & - & 1 & 3.7 \\
\hline $\begin{array}{l}\text { Ataque/atentado contra } \\
\text { comisaría o retén }\end{array}$ & 1 & 1 & - & - & - & 2 & 7.4 \\
\hline $\begin{array}{l}\text { Aviso de bomba o falsa } \\
\text { bomba }\end{array}$ & 2 & 1 & 1 & - & - & 4 & 14.8 \\
\hline $\begin{array}{l}\text { Bomba en edificio } \\
\text { (no considera edificios } \\
\text { policiales no religiosos) }\end{array}$ & - & - & 1 & 1 & 1 & 3 & 11.1 \\
\hline $\begin{array}{l}\text { Bomba en edificio de } \\
\text { carabineros }\end{array}$ & - & - & - & - & 1 & 1 & 3.7 \\
\hline $\begin{array}{l}\text { Bomba en templo o } \\
\text { iglesia }\end{array}$ & 3 & - & - & 1 & - & 4 & 14.8 \\
\hline Disparo contra carabineros & - & - & - & 1 & - & 1 & 3.7 \\
\hline Total & 16 & 3 & 2 & 3 & 3 & 27 & 100 \\
\hline Porcentaje & 59.3 & 11.1 & 7.4 & 11.1 & 11.1 & 100 & \\
\hline
\end{tabular}

periodo y los templos o iglesias mormonas fueron los objetivos más frecuentes. A continuación, se describirá gran parte del total de las acciones de violencia política desarrolladas entre 1990 y 1994.

Como ya se señaló, el año 1990 fue aquel con mayor cantidad de acciones de violencia política registradas en la prensa local. Para el mes de enero de ese año, es posible encontrar la primera de estas acciones, correspondiente a una declaración entregada a El Austral de Osorno, en la que el FPMR advertía tanto a los habitantes del sector de Rahue Alto, como de Osorno en general, debido a la falta de apoyo hacia aquellos a quienes denominaban representantes del pueblo. Esta advertencia fue realizada en el marco del aniversario del Partido Comunista. ${ }^{55}$

No hubo registros de nuevas acciones sino hasta el mes de junio. Aquí el periódico local describió la existencia de un supuesto artefacto explosivo en la Plazuela Yungay de la ciudad. Respecto a este, se señaló que: "el presunto artefacto explosivo contenía restos de comida, un cordel que simulaba detonadores y algunos panfletos alusivos al Frente Manuel Rodríguez.También se pudo establecer que el

55. "Frente Manuel Rodríguez advierte a rahuinos que habrá represalia", El Austral de Osorno (Osorno) 5 de enero de 1990. 
acto fue reivindicativo a través de un llamado telefónico a un medio de comunicación de esta ciudad, por el mencionado grupo extremista". ${ }^{56}$

Una acción similar fue registrada dos días después, sin embargo, en esa ocasión fueron dos las supuestas bombas, una presumiblemente instalada en el acceso a la Población Balmaceda y la otra en "un carrito manicero que permanecía a lo menos un par de horas en calle Eduvigis con Bilbao". ${ }^{57}$ Esta vez, la autoría de los hechos recayó en el MIR, ya que quienes participaron en estas acciones "procedieron a izar una bandera del Movimiento de Izquierda Revolucionaria".58

Para el 26 de julio del mismo año, en El Austral de Osorno se llegó a hablar de una escalada terrorista, debido a tres hechos: el robo de un taxi y la retención de su conductor al interior del vehículo, el uso de dicho automóvil para el posterior intento de asalto a una joyería y, por último, al atraco a la estación de ferrocarriles de la ciudad. Al respecto, en el periódico local se señaló:

Para algunos, el secuestro y el asalto [...] tendría corte delictual, en tanto que el atraco a la estación ferroviaria, tendría una connotación extremista o subversiva. [...] en fuentes extraoficiales se dijo que los panfletos encontrados en el recinto de Ferrocarriles, con el pie de firma del Mapu, del Frente Juvenil Lautaro y del Frente Revolucionario Lautaro, estarían indicando que las acciones fueron netamente subversivas. De las tres organizaciones, la última sería la que estaría seleccionando a sus "combatientes" y que el secuestro y los asaltos serían una especie de "exámenes" que estarían rindiendo sus militantes. ${ }^{59}$

Cabe destacar, respecto a lo último señalado en la cita anterior, que la idea de un reclutamiento en la ciudad — sobre todo en los liceos - por parte del MAPULautaro fue desarrollada de manera recurrente en el periódico. Esto se puede apreciar en las ediciones del 28 y 30 de septiembre, con la inclusión de las notas de prensa "Liceanos se mostraron impactados por el 'reclutamiento lautarista" y "Los liceanos condenaron acción de los lautaristas en colegios", respectivamente. ${ }^{60}$

En la edición del 27 de julio de El Austral de Osorno se describió un nuevo robo de taxi y posterior asalto, pero esta vez tuvo como objetivo final una gasolinera en la aledaña comuna de Purranque. ${ }^{61}$ A partir de lo ocurrido el 26 y 27 de julio, tanto por parte de los taxistas como de los carabineros existió un claro rechazo hacia estos hechos, donde incluso se señaló la posible existencia de amenazas de muerte a los

56. "Expectación por supuesto artefacto explosivo", El Austral de Osorno (Osorno) 17 de junio de 1990.

57. "Pánico por falsas alarmas de bombas en Balmaceda y Eduvigis", El Austral de Osorno (Osorno) 19 de junio de 1990.

58. "Pánico por falsas alarmas"

59. "Escalada terrorista sacudió a Osorno", El Austral de Osorno (Osorno) 26 de julio de 1990.

60. "Liceanos se mostraron impactados por 'reclutamiento lautarista", El Austral de Osorno (Osorno) 28 de septiembre de 1990; "Los liceanos condenaron acción de los lautaristas en colegios", El Austral de Osorno (Osorno) 30 de septiembre de 1990.

61. "Secuestraron a otro taxista y asaltaron una bencinera", El Austral de Osorno (Osorno) 27 de julio de 1990. 
taxistas por parte de algunos militantes de estos grupos. ${ }^{62}$ Los carabineros, en conjunto con la prensa local, buscaron evidenciar la relación entre los hechos (robos, asaltos y atraco a la estación de ferrocarriles) y los grupos que se los adjudicaron.

Ayer un avezado policía dijo que "estamos ante la presencia de dos grupos subversivos, pero que pertenecen a una misma camada”. Explicó que por un lado está el Frente Juvenil Lautaro que se adjudicó el asalto y robo de armas de la estación ferroviaria de Osorno y el Frente Manuel Rodríguez que hizo suya la autoría del secuestro y asalto a la bencinera de Purranque. [...] Los panfletos regados por los "lautaristas" en la Estación de Ferrocarriles y los llamados a emisoras locales del Frente Manuel Rodríguez indican claramente que "fueron acciones del tipo subversivo". ${ }^{63}$

Al respecto, otro elemento destacado por la prensa local fue la participación de mujeres en los hechos. En efecto, para el atraco a la estación ferroviaria se indicó que fue una mujer quien dirigió esta acción, y se señaló además que "Extremista emulando a la 'mujer metralleta' impartió las órdenes", ${ }^{64}$ actuar que quedaría registrado gracias al relato del guardia de la estación: "Ella dio la orden: llévenlo a la guardia... vamos, caminen, rápido". ${ }^{65}$

De acuerdo con lo señalado en la prensa local, respaldada por los cuerpos policiales, se estableció la estación de ferrocarriles como un objetivo de cierta recurrencia por parte de los grupos armados. Así, para el sábado 18 de agosto de 1990 quedó registrado un nuevo atraco a la estación, esta vez frustrado por detectives locales: "el hecho se registró pasada la medianoche del miércoles, día del aniversario del movimiento Manuel Rodríguez, cuando un grupo de seis de sus integrantes, se disponía a perpetar [sic] un atraco en la Estación de Ferrocarriles del Estado, de esta ciudad". ${ }^{66}$

Otras acciones registradas durante el año 1990 fueron: a) el asalto al casino del Instituto Profesional Osorno (IPO) — actual Universidad de Los Lagos - a fines de septiembre, donde además se encontraron rayados mensajes firmados con la sigla MR, de las Milicias Rodriguistas; ${ }^{67}$ b) un atentado contra el Fuerte Reina Luisa; c) la detonación de bombas en templos mormones y d) un atentando contra un retén de carabineros. Estas últimas tres acciones fueron en cierto modo emuladas en años posteriores.

Respecto al Fuerte Reina Luisa de Osorno, fuerte militar ubicado a orillas del río Rahue y construido a fines del siglo XVIII, la primera acción relacionada con este ocurrió en octubre de 1990, cuando los cañones del Fuerte fueron lanzados

62. "Osorninos sorprendidos ante ola de violencia”, El Austral de Osorno (Osorno) 27 de julio de 1990.

63. "Policía: son todos de una misma "camada", El Austral de Osorno (Osorno) 28 de julio de 1990.

64. "Mujer dirigió ataque a la Estación de Ferrocarriles", El Austral de Osorno (Osorno) 30 de julio de 1990.

65. "Mujer dirigió ataque". Énfasis en el original.

66. "A balazos frustraron atraco a la estación”, El Austral de Osorno (Osorno) 18 de agosto de 1990.

67. "Rodriguistas asaltaron casino del IPO”, El Austral de Osorno (Osorno) 27 de septiembre de 1990. 
al río y, además, se rayaron mensajes en oposición a la visita de los reyes de España al país. ${ }^{68}$ El periódico local señaló que:

La acción violentista fue reivindicada por el grupo denominado Frente Patriótico Manuel Rodríguez seccional Osorno, cuyos integrantes señalaron tomar parte de los grupos de colaboración y solidaridad con el pueblo indígena de la región. [...] Una persona que se identificó con el nombre de Raúl, llamó a las 12 horas con 10 minutos de ayer a la redacción de este diario en nombre del Frente Patriótico Manuel Rodríguez, cuyo movimiento se adjudicó el atentado cometido contra las instalaciones del Fuerte Reina Luisa ubicado a 60 metros del puente San Pedro de esta ciudad. ${ }^{69}$

Además, según afirmó el periódico, "fueron encontrados panfletos reivindicando las inquietudes del pueblo indígena [Mapuche-williche] y solicitando la devolución de las tierras ocupadas por los españoles que llegaron hace 500 años al continente", ${ }^{70}$ lo que agregaría una nueva dimensión a este tipo de hechos, pero que no sería tan extraña, en vista de que la ciudad de Osorno se encuentra en territorio mapuche y los mapuche-williche y/o mapuche en general han desarrollado procesos de resistencia de larga data en sus territorios, frente al colonialismo español y del Estado chileno. Además, algunas de las personas que participaron en las organizaciones rebeldes en Osorno tuvieron entre sus motivaciones la reivindicación de la lucha mapuche. ${ }^{71}$ Es interesante señalar que algunos años después, en agosto de 1999, nuevamente los cañones del Fuerte Reina Luisa fueron lanzados al río en el marco del apoyo y la reivindicación de las demandas de los mapuche. ${ }^{72}$

El segundo hecho registrado en el Fuerte ocurrió dos años después del primero, en octubre de 1992, pero esta vez se trató de la instalación y detonación de una bomba. Sin embargo, al igual que en 1990, se hizo alusión a los mapuche-williche: "En el lugar se encontraron panfletos que llamaban a la subversión, firmados por el Partido MAPU, y que decían: ‘Tierra y soberanía para el pueblo mapuche!”. ${ }^{73}$ Las iglesias y templos mormones fueron objeto de este tipo de actos en al menos cuatro ocasiones. La primera de ellas data del mes de diciembre de 1990, y correspondió a un templo mormón ubicado en el sector de Francke:

Un artefacto incendiario fue lanzado en la madrugada de ayer al templo de la Iglesia de Jesucristo de los Santos de los Últimos Días, ubicado en el populoso sector de Francke, donde causó

68. "Violentistas atacaron fuerte Reina Luisa y lanzaron cañones al río", El Austral de Osorno (Osorno) 18 de octubre de 1990.

69. "Violentistas atacaron fuerte".

70. "Violentistas atacaron fuerte".

71. Miguel Sepúlveda Chávez, "Militancia-instrumentalista y subalternidad: la experiencia de un grupo de subversivos en la ciudad de Osorno, 1986-1992. Influencias, sueños y motivaciones", Espacio Regional. Revista de Estudios Sociales 1.14 (2017): 119-120.

72. "Cañones al Rahue”, El Austral de Osorno (Osorno) 28 de agosto de 1999.

73. "Bombazo en Fuerte Reina Luisa”, El Austral de Osorno (Osorno) 6 de octubre de 1992. 
daños de consideración en el acceso al edificio sin que se registraran desgracias personales en esta ciudad. La acción fue adjudicada por una agrupación extremista juvenil a través de un llamado telefónico anónimo recepcionado en emisoras locales, donde se anunció que el atentado tenía el propósito de repudiar la presencia del Presidente Norteamericano George Bush en el país. [...] También se informó que en el lugar [Francke] fueron encontrados panfletos pertenecientes al Grupo Lautaro y Ché Rebelde, en los que llaman a la subversión y repudian la visita del Jefe de Gobierno Norteamericano a Chile. ${ }^{74}$

Este hecho, según lo que informó el periódico, fue el tercero de las mismas características:

Cabe recordar que es la tercera acción de subversivos que afecta a los templos mormones en esta ciudad, siendo el primero en la Iglesia ubicada en calle Matta esquina Rodríguez donde elementos desconocidos pusieron un artefacto explosivo, ocasionando daños en la puerta de ingreso al local. Una acción similar sufrió el templo ubicado en Rahue Alto lugar donde fue puesto un artefacto que causó destrozos en los ventanales del edificio, sin víctimas fatales. ${ }^{75}$

En tanto, para esa misma semana se registraron al menos cuatro hechos similares en distintas comunas de la Región Metropolitana de Santiago. ${ }^{76}$ Estos ataques a templos mormones se insertaron en una actitud de rechazo a nivel nacional respecto a este tipo de edificios, que fueron vistos como "lujosos santuarios de dominación", ${ }^{77}$ y estas acciones se justificaron como un aporte "contra la intervención yanqui en América Latina". ${ }^{78}$ En la ciudad de Osorno, la última bomba registrada durante el periodo analizado en un templo mormón fue en octubre de 1993. Nuevamente se trató de uno de los templos pertenecientes a la Iglesia de los Santos de los Últimos Días, esta vez el ubicado en Avenida Pacífico, en el sector de Rahue Alto. ${ }^{79}$

El ataque contra el retén de carabineros del sector de Francke fue la última acción registrada en el año 1990. Este hecho, según El Austral de Osorno, fue el primero de su tipo en la ciudad, por lo cual, tuvo un impacto mediático bastante importante. En su edición del 28 de diciembre de 1990, el periódico entregó los siguientes detalles del suceso: "Dos sujetos jóvenes que robaron un taxi colectivo dispararon anoche 36 impactos de bala en contra del Retén de Carabineros de Pampa Alegre, en el populoso barrio Franke, en esta ciudad. [...] En el intertanto, en una emisora local, una voz anónima reivindicó el atentado al Frente Lautaro". 80

74. "Bombazo en templo mormón de la población Francke", El Austral de Osorno (Osorno) 7 de diciembre de 1990

75. "Bombazo en templo mormón de la población".

76. "Ola de atentados contra restaurantes y templos", El Austral de Osorno (Osorno) 7 de diciembre de 1990.

77. Partido MAPU, El Pueblo Rebelde Vencerá 16 (Santiago) 1986: 10.

78. Partido MAPU 10.

79. “Bombazo en Templo Mormón”, El Austral de Osorno (Osorno) 8 de octubre de 1993.

80. "Ametrallado retén de carabineros de Franke", El Austral de Osorno (Osorno) 28 de diciembre de 1990. 
En las siguientes ediciones del periódico local, se publicaron una serie de notas de prensa y reflexiones respecto a estos hechos. Así, es posible encontrar en la edición del 29 de diciembre del mismo año las notas "La criminalidad en Osorno" y "Repudio unánime al atentando", 82 en las que respectivamente se reflexionó respecto a "la ola de violencia [...] presente en las últimas semanas con una seguidilla de crímenes y asaltos" ${ }^{83}$ y se mostró el rechazo por parte de algunos actores y sectores de la sociedad al ataque al retén. Asimismo, en esa edición se agregaron detalles respecto al hecho, y nuevamente se destacó la participación femenina, al señalar que una "mujer encabezó comando extremista". ${ }^{84}$ Dos hechos similares fueron registrados en años posteriores. El primero de ellos, en el mes de marzo de 1991, esta vez en el retén de carabineros ubicado en el sector de Ovejería.

Un atentado a balas sufrió anoche el retén de Ovejería, por parte de dos sujetos que se movilizaron en un taxi colectivo [...] los dos sujetos a bordo del taxi colectivo se dirigieron hacia el cuartel policial por el sector Costanera y al pasar frente a él, a una velocidad moderada, comenzaron a disparar varias ráfagas que impactaron en la fachada del inmueble, sin alcanzar a herir a nadie. [...] Los antisociales, minutos antes de perpetrar su condenable atentado "sembraron" de miguelitos varias calles de Rahue y los accesos al puente San Pablo. ${ }^{85}$

El segundo y último ataque registrado a un retén de carabineros fue también la última acción de violencia política registrada en el periodo, y ocurrió en octubre de 1994. En esta ocasión, se describió la explosión de un artefacto en la tenencia de carabineros de Rahue Alto, ubicada en la calle Guatemala, esquina con Pilcomayo. ${ }^{86}$ Después de este hecho, no hay registros de acciones de violencia política en la prensa local sino hasta abril de 1997, cuando se dio cuenta de un cadenazo que dejó sin electricidad a parte importante de la ciudad, acción cuya autoría se desconoce. ${ }^{87}$

Otro tipo de acciones de las que existe registro en el periodo revisado fueron los disparos a carabineros ${ }^{88}$ los avisos falsos de bombas, uno de ellos en marzo de $1991,{ }^{89}$ y el segundo en enero de $1992,{ }^{90}$ el asalto a la Financiera Condell ${ }^{91}$ y la instalación de artefactos explosivos. En referencia a lo último, en la edición del

81. "La criminalidad en Osorno", El Austral de Osorno (Osorno) 29 de diciembre de 1990.

82. "Repudio unánime al atentando", El Austral de Osorno (Osorno) 29 de diciembre de 1990.

83. "La criminalidad en Osorno".

84. "Repudio unánime".

85. "Ametrallaron el retén de Ovejería”, El Austral de Osorno (Osorno) 27 de marzo de 1991.

86. "Bombazo en Tenencia de Carabineros en Rahue Alto", El Austral de Osorno (Osorno) 29 de octubre de 1994.

87. "Cadenazo dejó a Osorno a oscuras", El Austral de Osorno (Osorno) 26 de abril de 1997.

88. "A balazos atacaron a garita de Carabineros", El Austral de Osorno (Osorno) 1 de junio de 1993.

89. "Cuatro alarmas de falsas bombas", El Austral de Osorno (Osorno) 5 de marzo de 1991.

90. "Falsa alarma de bomba movilizó a la policía”, El Austral de Osorno (Osorno) 25 de enero 1992.

91. "A mano armada asaltaron financiera", El Austral de Osorno (Osorno) 25 de marzo de 1994. 
Tabla 2. Cantidad de acciones de violencia política por autoría

\begin{tabular}{|c|c|c|c|c|c|c|c|}
\hline Organizaciones o grupos & 1990 & 1991 & 1992 & 1993 & 1994 & Total & Porcentaje \\
\hline $\begin{array}{l}\text { MAPU-Lautaro, Grupo Juvenil } \\
\text { Lautaro, Frente Revolucionario } \\
\text { Lautaro, Partido MAPU, Frente } \\
\text { Juvenil Lautaro }\end{array}$ & 3 & 2 & 1 & 1 & 1 & 8 & 29.6 \\
\hline $\begin{array}{l}\text { Frente Patriótico Manuel } \\
\text { Rodríguez (FPMR) }\end{array}$ & 9 & - & - & - & - & 9 & 33.3 \\
\hline $\begin{array}{l}\text { Movimiento de Izquierda } \\
\text { Revolucionaria (MIR) }\end{array}$ & 1 & - & - & - & 0 & 1 & 3.7 \\
\hline $\begin{array}{l}\text { Ejército Guerrillero de los Pobres- } \\
\text { Patria Libre }\end{array}$ & - & - & - & - & 1 & 1 & 3.7 \\
\hline Autoría no identificada & 3 & 1 & 1 & 2 & 1 & 8 & 29.6 \\
\hline Total & 16 & 3 & 2 & 3 & 3 & 27 & 100 \\
\hline Fuente: El Austral de Osorno [Osorno] 1990-1994. & & & & & & & \\
\hline
\end{tabular}

19 de diciembre de 1993, El Austral de Osorno describió la detonación de uno de estos artefactos en el edificio de SAESA, S.A., empresa distribuidora de electricidad ubicada en la calle Bulnes, en el sector centro de la ciudad. ${ }^{92}$ Igualmente, se registró en el periódico local una bomba instalada en la agencia local del periódico El Mercurio, ubicada igualmente en calle Bulnes, en febrero de 1994. ${ }^{93}$

Cabe destacar que, en conformidad con las autorías adjudicadas por El Austral de Osorno a las acciones descritas, un porcentaje importante corresponde al FPMR, así como todas las que se llevaron a cabo en el año 1990. Además, al comparar la tendencia nacional, según la cual el 56\% de las acciones subversivas registradas entre 1990 y 1992 fueron desarrolladas por el MAPU-Lautaro, ${ }^{94}$ con lo ocurrido a nivel local, se encontraron diferencias, ya que para el periodo señalado fue el FPMR el que ejecutó la mayor cantidad de acciones en Osorno. No obstante, existe un número importante de acciones con una autoría no identificada que podrían modificar dicha tendencia.

Respecto a los tipos de acciones de violencia política de las dos organizaciones con mayor actividad registrada a través de la prensa local, se puede señalar que, en el caso del FPMR, poco más de la mitad de sus acciones corresponden a la categoría de asalto o robo (cinco), mientras que las restantes se dividen en amenazas

92. "Artefacto explosivo detonó en Saesa”, El Austral de Osorno (Osorno) 19 de diciembre de 1993.

93. "Pusieron una bomba en agencia de El Mercurio", El Austral de Osorno (Osorno) 5 de febrero de 1994.

94. Álvaro Soto Carmona, "Violencia política y transición a la democracia: Chile y España”, Violencia y transiciones políticas a finales del siglo XX: Europa del Sur - América Latina, dirs. Sophie Baby y otros (Madrid: Casa de Velázquez, 2009) 120. 
(dos), atentado contra edificación (uno) y aviso de bomba (uno). A su vez, para el MAPU-Lautaro, la mitad de sus acciones corresponden al uso de bombas (cuatro), mientras que la otra mitad corresponde a atentado contra retén de carabineros (dos) y asaltos (dos). En la Tabla 2 se puede ver el detalle de la cantidad de acciones en relación con las autorías identificadas o adjudicadas por la prensa local.

Por último, es importante reiterar que el conjunto de este tipo acciones fue, desde las visiones hegemónicas nacionales y locales, constantemente relacionado con las ideas de delincuencia, crimen, peligro para la sociedad y la democracia, entre otras, lo que permitió deslegitimarlas e invisibilizar o eliminar su carácter político. Lo anterior, además fue permeado en distinto grado a la sociedad osornina. Así, por ejemplo, el 19 de noviembre de 1990, El Austral de Osorno publicó una columna de opinión en la cual seis personas hablaron sobre el denominado terrorismo a nivel general y local. ${ }^{95}$

\section{Consideraciones finales}

Al finalizar este trabajo, es posible decir, en primera instancia, que se refuerzan afirmaciones tales como la existencia de un primer momento, entre 1990 y mediados de 1991, en el que se concentraron la mayor cantidad de estrategias de resistencia y sobre todo aquellas de violencia política. Además, en el caso de Osorno, fue ese momento cuando se desarrolló una mayor variedad de acciones violentas. El fin de esta primera fase se corresponde con un fortalecimiento de los mecanismos y las estrategias puestos en práctica por el estado y los grupos hegemónicos para desarticular y eliminar los grupos y organizaciones rebeldes y sus procesos de resistencia.Asimismo, a partir de lo anterior, se da pie a una nueva etapa marcada por la disminución de las acciones violentas, así como también por la detención y el encarcelamiento de quienes fueron parte de la resistencia postdictatorial.

En segundo lugar, se puede apreciar que, a pesar del contexto desfavorable, no solo por lo ya descrito a lo largo del trabajo y enmarcado en el contexto nacional, sino también por las características propias de la ciudad de Osorno, que pueden ser resumidas en la existencia de un imaginario sociopolítico de esta como una ciudad clasista, elitista y conservadora - lo que tendría sustento en una serie de procesos históricos y sociales acontecidos en este territorio-, diversos grupos subalternos y/o subalternizados desarrollaron (y desarrollan) procesos de resistencia o contra la dominación, lo cual es reafirmado por quienes fueron y son parte de estos procesos:"Igual desmitificar un poco lo que siempre se hizo, o sea Osorno es una ciudad reaccionaria [...], fascista, [...] si bien, a modo general eso ocurra en la ciudad que es clasista [...] y todo eso, si hay una historia de resistencia en Osorno". ${ }^{96}$ En otras palabras, se puede ratificar la existencia de procesos y estrategias de resistencia para el periodo 1990-1994 en la ciudad de Osorno, así como la presencia de organizaciones

95. “Osorninos frente a: ...Actos Terroristas”, El Austral de Osorno (Osorno) 19 de noviembre de 1990.

96. Entrevista a Miguel. 
rebeldes armadas, lo que quedó registrado en la prensa local, principalmente por sus acciones de violencia política. Por otra parte, respecto al motivo por el cual mantuvieron dichos procesos y acciones para este periodo, uno de los actores protagonistas señaló lo siguiente:

Decidimos mantener nuestras formas de lucha. Desarrollamos acciones de sabotaje, de propaganda, que apuntaban en ese período contra los símbolos del poder fáctico, contra quienes hubiesen estado asociados al régimen dictatorial o que representasen la permanencia y avance del modelo neoliberal en Chile y de una democracia política controlada por la esfera militar [...] el tipo de acción que se desarrolló entre 1990 y 1994 fue de corte propagandístico militar, orientada a manifestar un desacuerdo profundo, una forma de lucha de resistencia alternativa a la transición que se estaba viviendo en ese momento. ${ }^{97}$

En cuanto a las organizaciones presentes en la ciudad de Osorno, y a partir de lo revisado en las secciones anteriores, es posible además asumir que aquellas que tuvieron una mayor actividad en el periodo estudiado fueron el FPMR y el MAPU-Lautaro, o algunas facciones o grupos ligados a estos. En este sentido, y a la vista de otros trabajos desarrollados con anterioridad, es necesario matizar lo referente a la actividad que llevaron a cabo estas organizaciones, debido a la existencia de un grupo de entre 10 y 12 personas que participaron y ejecutaron acciones de violencia política en el marco de estas, pero sin tener una militancia clara o tradicional en alguna de ellas ${ }^{98}$ por lo que cabe la posibilidad de que un número significativo de las acciones adjudicadas a las organizaciones nombradas (e incluso aquellas de las que no fue posible identificar su autoría) fueran realizadas por un mismo grupo de personas y no por organizaciones o grupos diferentes. La escasez de información o estudios en relación con situaciones específicas como las señaladas impide por ahora determinar si esto es más bien una particularidad de Osorno, o de algunos territorios en concreto, o si más bien se trata de algo que sucedió con relativa normalidad a lo largo del territorio nacional.

Es a partir de especificidades como la recién señalada, o de la posible relación entre estos grupos / organizaciones y sus integrantes con los mapuche-williche en este territorio — algo mínimamente esbozado en este trabajo-, que a futuro se podrá avanzar en reflexiones y estudios que permitan aportar no solo al conocimiento territorial / local, sino a debates más amplios, como la influencia de los contextos territoriales locales en procesos enmarcados en una lógica nacional o sobre cómo estas lógicas nacionales, tanto de control / dominación como de resistencia, se adaptan o son adaptadas a contextos diferentes a aquellos que consciente o inconscientemente son utilizados como modelos para el desarrollo de estas.

97. Dauno Tótoro Taulis, "Historia Prisionera. Entrevista a Pedro Rosas en la CAS", Santiago, octubre de 2004: 3. https://www.archivochile.com/Experiencias/exp_popu/EXPpopulares0013. pdf $(25 / 01 / 2021)$.

98. Sepúlveda Chávez, "Militancia-instrumentalista". 
Por último, cabe recordar el carácter parcial de lo revisado en este artículo, primero, en tanto que se ha trabajado mayormente con lo registrado por la prensa local, quedaron fuera los detalles, descripciones, análisis y otros elementos que pudieran aportar las personas que participaron de dichos procesos. En segundo lugar, en la medida en que este trabajo únicamente se ha centrado en una de las actuaciones o performances que componen lo que, inspirado en Charles Tilly, se podría comprender como un repertorio de resistencia, restando así la revisión de esas otras estrategias desarrolladas durante el periodo, lo que permitiría profundizar, complementar y contrastar lo aquí analizado. Así, queda esto como tarea pendiente para avanzar en un futuro en otras posibles investigaciones.

\section{Fuentes}

\section{Periódicos}

El Austral de Osorno (Osorno) 1990-1999.

El Pueblo Rebelde Vencerá (Santiago) 1986.

\section{Orales}

Miguel, entrevista realizada por Miguel Sepúlveda Chávez. Osorno, agosto de 2015. Miguel y Ricardo, entrevista realizada por Miguel Sepúlveda Chávez. Osorno, agosto de 2015.

Ricardo, entrevista realizada por Miguel Sepúlveda Chávez. Osorno, agosto, 2015.

\section{Bibliografía}

Acevedo Arriaza, Nicolás. "Continuidades en el Chile post-dictatorial: el accionar del MAPU-Lautaro y la respuesta de la Policía de Investigaciones en el gobierno de Patricio Aylwin (1990)". Revista Divergencia 4 (2013): 73-101.

Burgwal, Gerrit. Prácticas cotidianas de resistencia. Montevideo:Tierra Nueva, 1970.

Corporación de Promoción y Defensa de los Derechos del Pueblo (CODEPU). Informe Derechos Humanos 1990-1994. Santiago: [s.e.], 1994.

Feria Vázquez, Pedro. "Del mediterráneo al cono sur: las transiciones a la democracia de Chile, Portugal y España en perspectiva comparada”. Revista de Historia Social y de las Mentalidades 22.2 (2018): 103-135.

Follegati Montenegro, Luna. "Estrategias analíticas de la Transición a la Democracia: la clave del pasado como perspectiva de futuro”. Rosa 1 (2019): 41-61.

Foucault, Michel. Microfísica del poder. Madrid: La Piqueta, 1978.

Garretón, Manuel Antonio. Neoliberalismo corregido y progresismo limitado. Los gobiernos de la concertación en Chile, 1990-2010. Santiago: Editorial ArcisCLACSO, 2012.

Giraldo Díaz, Reinaldo. "Poder y resistencia en Michel Foucault". Tabula Rasa 4 
(2006): 103-122.

Goicovic Donoso, Igor. "Transición y violencia política en Chile (1988-1994)". Ayer 79.3 (2010): 59-86.

Inclán, Daniel. "Contrapuntos: la crueldad contra el cuidado (o cómo la violencia se hace cotidiana)". Bajo el Volcán 16.24 (2016): 13-31.

Inclán, Daniel y Aurelia Valero. "Reporte del tiempo: presente e historia”. Desacatos. Revista de Ciencias Sociales 55 (2017): 60-73. Doi: 10.29340/55.1804.

Jorquera-Álvarez, Tamara e Isabel Piper Shafir. "Revisión de estudios sobre violencias políticas realizados en la última década”. Psicoperspectivas 17.3 (2018):1-13.

Molina Valencia, Nelson. "Resistencia comunitaria y transformación de conflictos". Revista Reflexión Política 7.14 (2005): 70-82.

Monsálvez Araneda, Danny y Yerko Aravena Constanzo. "Interpretaciones historiográficas sobre la violencia política en Chile". Folia Histórica del Nordeste 32 (2018): 83-99. Doi: 10.30972/fhn.0323498.

Muñoz Sougarret, Jorge. "Introducción”. Osorno, la ciudad moderna del sur de Chile. Salubridad, sociabilidad y discursos. Primera mitad del siglo XX. Simón Fernández Parra y otros. Osorno: Editorial Universidad de Los Lagos, 2016.

Sánchez Aguilera, Víctor. El pasado de Osorno. La gran ciudad del porvenir. Osorno: Municipalidad de Osorno, 1948.

Scott, James C. Los dominados y el arte de la resistencia. Discursos ocultos. México: Ediciones Era, 2000.

Sepúlveda Chávez, Miguel. "Evolución del discurso anti-resistencia en la dictadura militar chilena. El caso de Osorno, 1973-1994”. Religación. Revista de Ciencias Sociales y Humanidades 1.3 (2016): 55-75.

."Mecanismos de control en la ciudad de Osorno: contexto de dictadura militar, 1973-1990”. Diálogos. Revista Electrónica de Historia 16.1 (2015):215-239. . "Mecanismos de resistencia en la ciudad de Osorno, en el contexto de dictadura militar, 1973- 1990". Scientia Plena 10.12 (2014): 1-12.

"Militancia-instrumentalista y subalternidad: la experiencia de un grupo de subversivos en la ciudad de Osorno, 1986-1992. Influencias, sueños y motivaciones". Espacio Regional. Revista de Estudios Sociales 1.14 (2017): 109-126. . "Osorno como territorio en disputa. Una revisión a través del imaginario hegemónico y los procesos de resistencia durante el siglo XX”. Identidades 20 (2021): 20-36.

Soto Carmona, Álvaro."Violencia política y transición a la democracia: Chile y España”. Violencia y transiciones políticas a finales del siglo XX: Europa del Sur - América Latina. Dirs. Sophie Baby y otros. Madrid: Casa de Velázquez, 2009.

Tótoro Taulis, Dauno. "Historia Prisionera. Entrevista a Pedro Rosas en la CAS". Santiago, octubre de 2004. https://www.archivochile.com/Experiencias/exp_popu/EXPpopulares0013.pdf (25/01/2021). 